\title{
Laundry Habits in Bangkok: Use Patterns of Products and Services
}

\author{
Dami Moon *, Eri Amasawa $₫$ and Masahiko Hirao \\ Department of Chemical System Engineering, The University of Tokyo, Tokyo 113-8656, Japan \\ * Correspondence: moon@pse.t.u-tokyo.ac.jp; Tel.: +81-3-5841-7959
}

Received: 14 June 2019; Accepted: 8 August 2019; Published: 19 August 2019

check for updates

\begin{abstract}
This study aimed to define the use of product-service system (PSS) associated with laundry businesses, such as coin-operated self-service laundromats (CL) and laundry services (LS), in order to get a better understanding of the environmental implications of PSS in laundry habits in Bangkok, Thailand. The motivation to use PSS could vary according to the specific consumer needs often defined by cultures, and therefore the environmental impacts from the PSS use would result differently from country to country. Questionnaires and in-depth interviews were conducted with Bangkok residents to determine the laundry habits related to the use of PSS. As a result, the use of private washing machines (PW) was found to be the main option, and CL and LS were used as an additional option in the laundry habits. The most widely observed use pattern in Bangkok was the use of CL as an alternative to PW instead of buying a new machine for a new life in dormitories or other residences away from home. At that time, hand washing (HW) was also used for saving money and for the cleanliness. Regarding the environmental potential, the relationship between the PSS users and laundry habits was specifically analyzed. The group who uses PSS frequently tended to do laundry less often than those who only use PW. Meanwhile, the need for even more services is also expected to increase among the PSS users. The need to improve the quality of laundry is expected to increase with the improvement of quality of living in Bangkok in the near future. However, at the same time, these observations imply that a change of consumer behaviors related to the use of PSS determines the resulting energy consumption and environmental burdens. To further clarify sustainable consumption and production systems, a quantitative analysis of the environmental impact of the laundry habits remains as a future task.
\end{abstract}

Keywords: sustainable consumption and production; laundry habits; product-service system (PSS); sharing economy; private washing machine; coin-operated self-service laundromat; laundry service; consumer acceptance

\section{Introduction}

In the past, laundry has been a considerable burden on households in terms of time and effort. Nowadays, machines, rather than human power, do some tasks, such as washing, rinsing, spin-drying, and drying by consuming water, electricity, laundry detergent, and fabric softener, and process time as resources [1,2]. Following the mechanization of laundry work, various types of laundry-related businesses offering services and the utilization of product functions were introduced as an alternative to doing laundry at home [3]. This represents a shift in consumption patterns from ownership to service-based consumption to meet the needs of consumers and it is often referred to as a product-service system (PSS, acronyms used in this study arranged in Table A1). It has been suggested that PSS could reduce the number of machines for production and sale by sharing machines among consumers [4]. This suggests that the use of PSS can reduce the amount of resources and energy use in the shared community. In addition, it is also possible to increase energy efficiency through the use of advanced 
equipment in the use stage [4]. For these reasons, the use of PSS by consumers is widely considered as a useful contribution to environmental sustainability by departing from the conventional framework of mass production and consumption [3,5-7].

These environmental impacts are theoretically possible, although empirical evidence in support of the theory is still limited according to detailed reviews [2,7-9]. The reason is that the environmental impact of laundry habits cannot be simplified to specific values; they have to be addressed considering variations in cultures and lifestyle affecting use patterns at different locations [10]. For example, laundry habits such as the taste of washing machine (washer) type, ownership of washer and dryer, pre and post treatment, and laundry temperature preferences differ by country [2,11]. Moreover, PSS is also provided in various ways to adapt to these laundry habits formed by consumers who have different needs and interests in each country. Although many studies have introduced PSS as eco-effective and eco-innovative practices to achieve sustainable consumption and production, the environmental impact of the utilization of PSS can vary according to laundry habits [4,11-16]. Therefore, it is necessary to clarify the role of PSS in the laundry habits and to propose country-specific environmentally friendly laundry habits aiming at a more sustainable consumption and production system [17]. As part of a study to investigate the environmental impacts of PSS associated with laundry habits (laundry PSS), Amasawa et al. (2018) [18] have examined the potential for greenhouse gas (GHG) emissions reduction through laundry PSS, with a focus on coin-operated self-service laundromats (CL) in Japan, where the ownership rate of private washers (PW) is almost 100 percent [19]. In addition to using PW in their daily lives, Japanese consumers tend to use laundromats as an additional method to meet distinct consumer needs, that is, a laundromat is used to wash large-size items such as blankets or coats, to use large-capacity machines, or to dry laundry using a tumble-dryer during the rainy season. These studies indicated that the use of CL is less likely to reduce GHG emissions compared to using PW in Japan [18].

Compared to Japan, the ownership rate of PW in Thailand is still far less than 100 percent (approximately 53 percent in 2012); it is one of the countries where CL and commercial laundry services (LS) businesses are widely used [20,21]. The motivation to use PSS may be different according to the specific needs and focus of residents in Bangkok, and the environmental impacts from the use of PSS may also produce different results from other countries where most consumers own a PW. However, few studies have investigated the environmental impact of the use of PSS and PW in laundry habits in countries in which PW have yet to become widespread, such as Thailand [3,22]. This study aimed to define the use of CL and LS and to clarify the environmental implications of PSS in laundry habits in Bangkok, Thailand. Specifically, this paper focused on identifying the role of CL and LS and the typical use pattern in daily laundry habits in Bangkok. A resident survey was conducted, with a random sample of around 200 respondents living in Bangkok. Based on the responses obtained from the survey, respondents were classified into groups. The role of CL and LS and the usage patterns in laundry habits were examined by summarizing the frequency of use and the type of laundry. This paper sheds light on the potential to reduce environmental impacts on laundry habits by using PSS in Bangkok.

\section{Residential and Living Environments in Bangkok}

Thailand, a Southeast Asian country located in tropical regions, has a population of more than 69 million, and approximately 12 percent of the total population is concentrated in the capital Bangkok [23]. The capital has a very high population density of roughly 5300 people per square kilometer compared to the rest of the country, which has a density of 135 people per square kilometer. The high population density in Bangkok affects residential housing types. In municipal areas, including Bangkok, approximately 53 percent of housing consists of detached houses, which is about 36 percent lower than non-municipal areas, in which detached houses account for 89.8 percent of housing. Housing with insufficient space for drying laundry naturally, such as shop-houses, apartments, and townhouses, account for nearly 41 percent of the total housing (18.4 percent, 12.7 percent, and 9.9 percent, respectively). Moreover, in Bangkok, short-term residences such as dormitories and lodging for students and workers from the provinces account for 31.5 percent, which is 23 percent 
higher than in non-municipal areas (7.7 percent) [23]. The current status of residential and living environments in Bangkok may be the reason that there are a large number of laundry PSS-related businesses, and these are commonly used by those living in Bangkok.

\section{Methods}

\subsection{Residents Survey in Bangkok: Questionnaires and In-Depth Interviews}

To investigate the current status of PSS use in the laundry habits in Bangkok, a face-to-face questionnaire survey and in-depth interviews were carried out between the 22nd and the 24th of October 2018 on approximately 200 Bangkok residents (over 18 years old) who do their own laundry. Figure 1 shows the survey areas in Bangkok and the surrounding area. The survey was an intercept survey; it was performed in the specific places where the PSS users can be contacted, that is, dormitories for students and office workers, or near CL or LS, as well as in public places such as shopping malls, bus stations, marketplaces, and public squares. Here, a dormitory is defined as a type of shared house in which college students or company workers live together. The dormitory is generally composed of two spaces: a private space for a bed and relaxing and a public space for cooking, washing, or recreation, which is shared with others.

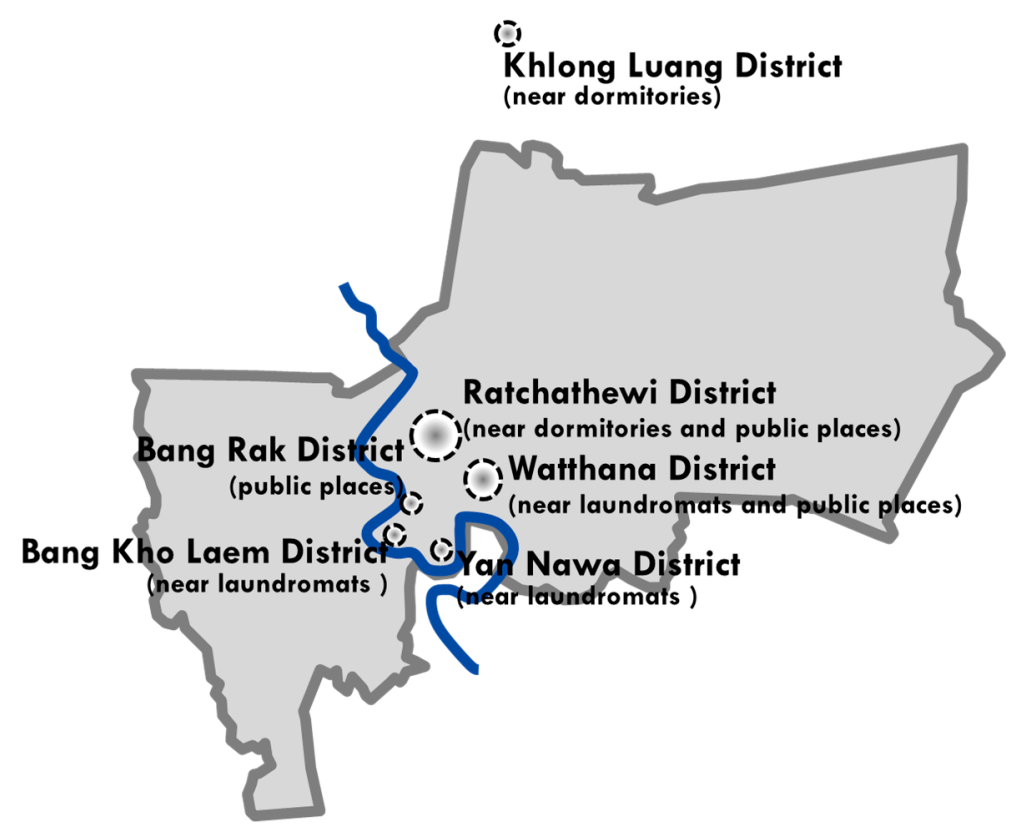

Figure 1. Survey areas in Bangkok.

The survey was divided into two parts: questionnaire and in-depth interview, as summarized in Table 1. First, we received around 200 responses to the questionnaire, which took roughly five minutes to complete and included questions regarding demographic information, how they wash their clothes, and how they use PW, CL, and LS. Secondly, in-depth interviews were performed with 74 individual respondents who were willing to participate after completing the questionnaire. During the in-depth interviews, the respondents provided detailed answers to the questionnaire such as the reason for the use of PW, CL, and LS. To appropriately communicate and record responses, the team of interviewers basically consisted of three members; one (Thai) was the role of communicating with interviewees, another (Thai) was the role of interpreting while listening to the content of conversation between interviewer and interviewees, and the other wrote down from the dictation in order to put on the record. 
Table 1. An outline of a questionnaire survey and an in-depth interview survey.

\begin{tabular}{|c|c|c|}
\hline Category & Questionnaires & In-Depth Interviews \\
\hline Survey period & \multicolumn{2}{|c|}{ October $22-24$ in 2018} \\
\hline Survey method & \multicolumn{2}{|c|}{ Face-to-Face survey (intercept survey) } \\
\hline Respondents & Residents in Bangkok & Questionnaire survey respondents \\
\hline Number of samples (n) ${ }^{1}$ & $\mathrm{n}=192(207)$ & $\mathrm{n}=69(74)$ \\
\hline Gender distribution & Male: $38.8 \%$, Female: $61.2 \%$ & Male: $35.2 \%$, Female: $64.8 \%$ \\
\hline \multirow{2}{*}{ Age distribution } & Under 20s: $26.3 \%, 20 \sim 39: 50.0 \%$, & Under 20s: $27.1 \%, 20 \sim 39: 51.4 \%$, \\
\hline & 40 59: 19.5\%, 60 79: 4.2\% & 40 59: $15.7 \%, 60 \sim 79: 5.7 \%$ \\
\hline Estimated time & $5 \mathrm{~min} /$ respondent & $10 \mathrm{~min} /$ respondent \\
\hline \multirow[t]{4}{*}{ Content } & $\begin{array}{l}\text { Demographic information (Gender, age, } \\
\text { occupation, income, household numbers, } \\
\text { housing type) }\end{array}$ & $\begin{array}{l}\text { Common questions (Frequency of } \\
\text { showering, water temperature for } \\
\text { shower or laundry, number of } \\
\text { wears per item of clothing, feeling } \\
\text { about drying clothing outside) }\end{array}$ \\
\hline & $\begin{array}{l}\text { Laundry habits (Type of machines for laundry } \\
\text { (own or use), hand washing (Pre-washing, Type } \\
\text { of clothes for hand washing)) }\end{array}$ & $\begin{array}{l}\text { Use of PW (Time and place to } \\
\text { purchase washer/dryer, intended } \\
\text { use for PW, use of PW) }\end{array}$ \\
\hline & $\begin{array}{l}\text { Use of PW (Type, frequency, drying method, } \\
\text { the necessity of tumble-dryer) }\end{array}$ & $\begin{array}{l}\text { Use of CL and LS (Intended use } \\
\text { for CL and LS, Feelings and } \\
\text { opinions about CL and LS) }\end{array}$ \\
\hline & $\begin{array}{l}\text { Use of CL and LS (Frequency, cost, reason for } \\
\text { using, additional service) }\end{array}$ & \\
\hline
\end{tabular}

\footnotetext{
${ }^{1}$ To obtain significant results, an effective sample excluding meaningless sample, in which "prefer not to answer (PNTA)" was chosen for all questions, was obtained from the total number of collected responses, and used for analyzing the data. The numbers in parentheses indicate the total number of respondents collected during the survey.
}

\subsection{Grouping the Respondents}

To determine laundry habits, respondents were divided into three groups based on their answers to the questions related to the current usage of PW, CL, and LS. Figure 2 presents the classification of the residents into three groups: PW-only, multi, and PSS-only.

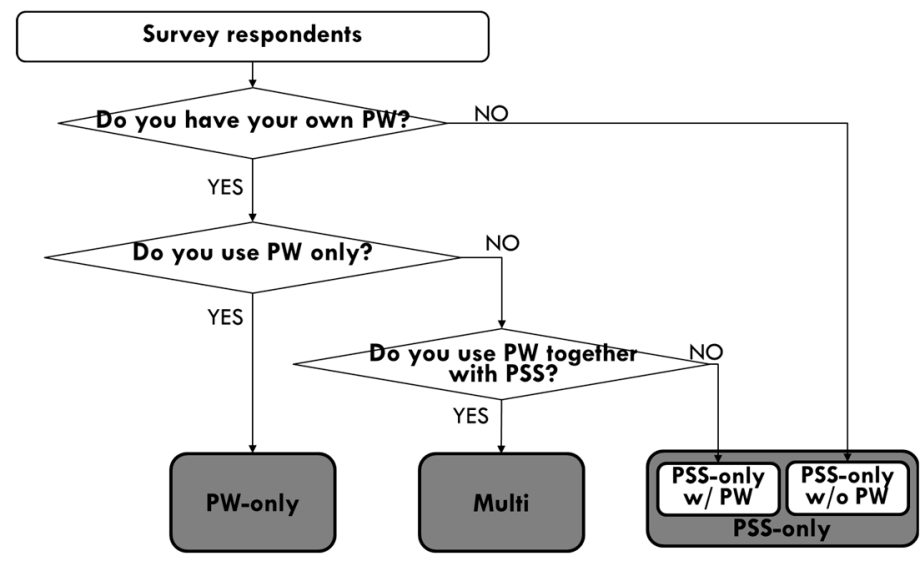

Figure 2. A flow diagram classifying respondents according to the current usage of private washers (PW) and product-service system (PSS) $(\mathrm{n}=192)$.

\subsection{Assessing the Role of Private Washers, Coin-Operated Laundromats, and Laundry Services}

Based on the 69 valid responses from the in-depth interviews, the role of PW, CL, and LS was assessed by measuring the range of intended use and frequency of use, as shown in Table A2. Here, intended use was defined as the type of clothing and fabrics for laundry. Intended use can be 
categorized into four main types of clothing and fabrics: all types, underwear and socks, formal clothes, and large-size laundry. Formal clothes included clothes that need to be ironed regularly such as school uniforms and shirts, and large-size laundry comprised clothes or fabrics that cannot be washed by hand such as blankets, curtains, sweaters, or jeans. Frequency of use was measured using a six-point Likert scale that ranged from "always", "usually", "often", "occasionally", "seldom", to "never". In addition, the reason for the choice of each laundry method was also organized according to the similar responses.

\section{Results}

\subsection{Questionnaire Survey Results: Laundry Habits by Group}

There are two main types of CL and LS that are widely used in Bangkok. The two types of CL are CL-outside and CL-inside. In the former type, vertical-axis (v-axis or top-load type) washers are similar to PW and are installed next to a building or on the street, which is typical in Bangkok. In the latter type, horizontal-axis (h-axis or front-load type) washers are installed inside a building, which is becoming popular in Bangkok. Tumble-dryers are also installed and are available to meet the requirement of CL users, unlike CL-outside, in which machines with additional drying functions such as washer-dryers or tumble-dryers are rarely seen. LS is a commercial laundry service that provides three services: water-based-washing, drying, and folding. For an additional fee, LS users also can receive additional services, such as ironing and delivery. According to LS operations managers, natural drying is preferred over machine-based drying due to the amount of sunlight in Bangkok. Here, LS is mainly referring to the regular laundering service. The way of washing and drying is quite different with the dry-cleaning service, which is another type of LS. Dry-cleaning service-related businesses are relatively minor compared to the regular laundering service-related business in Bangkok. Therefore, dry-cleaning service is excluded from the boundary of LS.

As shown in Figure 3, PW-only, multi, and PSS-only accounted for 34.9 percent, 36.4 percent, and 28.7 percent, respectively. In particular, the ownership rate of PW was approximately 80.2 percent. In addition, regardless of CL and LS, PSS constituted almost 65.1 percent of the total, in which the ratio of CL use and LS was 54.2 percent and 26.0 percent, respectively. It should be noted that the respondents were allowed to give multiple responses.

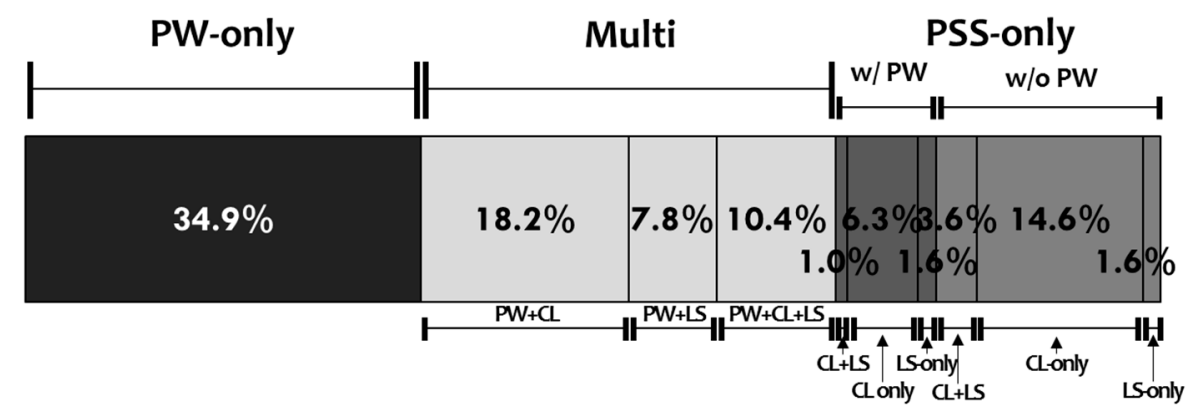

Figure 3. The percentage of respondents in each group $(n=192)$.

Figure 4 shows the yearly number of laundry cycles per respondent in each group. The number combines the use of PW, CL, and LS. The annual number of laundry cycles per respondent was roughly 189 cycles/year, in which the ratio of each method was 62.9 percent, 25.7 percent, and 11.4 percent, respectively. This frequency is similar to the figures for Western and Eastern Europe of 165-173 cycles/year [2]. In terms of the differences by groups, the multi group had 250 cycles/year, followed by the PW-only group with 183 cycles/year, and the PSS-only group with 120 cycles/year. The percentage of CL and LS use in the multi group accounted for 25.2 percent and 14.0 percent, respectively, while PSS-only group showed 74.5 percent and 25.5 percent, respectively. 


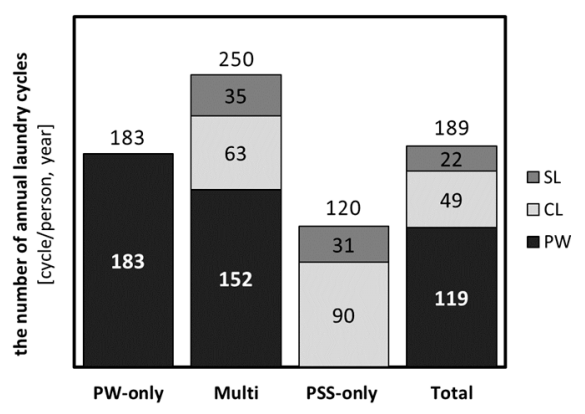

Figure 4. Annual number of laundry cycles by group ( $\mathrm{n}=192$, multiple responses).

Regarding the laundry done by hand washing $(\mathrm{HW})$, the ratio of users who pre-wash their laundry by hand and the type of clothing and fabrics washed by hand are shown in Figure 5. Around 31.4 percent of the respondents do their laundry by hand before using a machine (Figure 5a). Even though the differences among the three groups were not statistically significant $\left(\chi^{2}=4.280, d f=6, p=0.639\right)$, the multi group represented 18.6 percent, the $\mathrm{PW}$-only group represented 14.3 percent, and the PSS-only group represented 13.0 percent. For the type of clothing and fabrics laundered by HW, 34.5 percent of respondents indicated that they wash their underwear themselves. As shown in Figure $5 b$, the ratio of respondents who wash socks, shoes, shirts, skirts, and pants by hand was 19.6 percent, 17.6 percent, 15.5 percent, and 8.8 percent, respectively. Although the differences among the groups were not statistically significant $\left(\chi^{2}=8.074, d f=12, p=0.779\right)$, respondents who belong to the PSS-only group and the multi group tend to extend the type of clothes for washing by hand to shirts, skirts, and pants, not only underwear and socks. The reasons why Thai respondents wash by hand before doing laundry were found from the in-depth interviews. During the interview, they frequently mentioned the quality of the finished laundry related to cleanliness and well-finished laundry, as shown in the Table A2. They pre-wash by hand in order to ensure the quality of the laundry in addition to the use of washers in Bangkok.

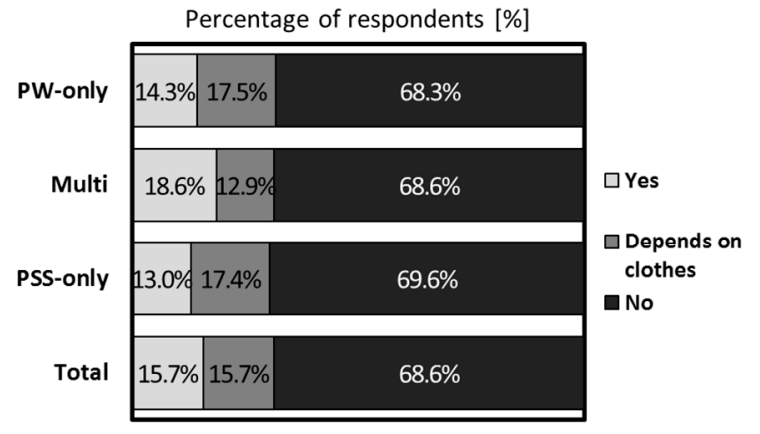

(a)

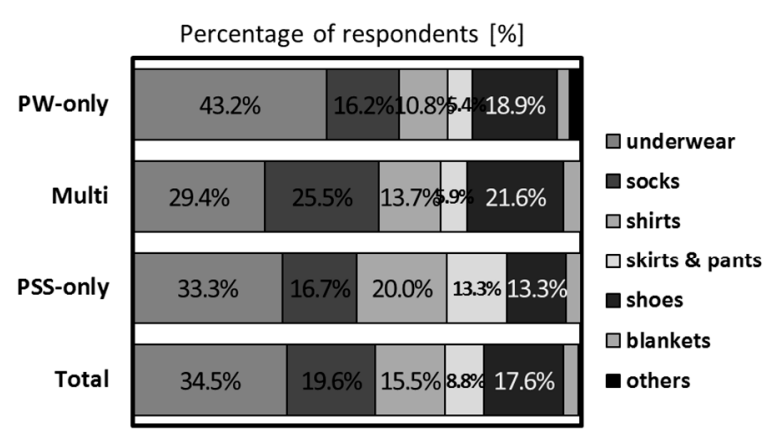

(b)

Figure 5. Results on hand washing (HW): (a) The ratio of users who pre-wash by hand $(\mathrm{n}=190)$; (b) The types of household clothing and fabrics $(n=118)$.

Figure 6 shows the responses drying clothing and fabrics. Approximately 89 percent of the respondents indicated that they usually dry their clothing and fabrics naturally whenever possible (Figure 6a). Among them, the ratio of drying outside and inside was 81.4 percent and 8.1 percent, respectively. On the contrary, only around 11 percent of respondents use a tumble-dryer to dry laundry. The differences among the proportion of drying methods by group was not statistically significant $\left(\chi^{2}=4.545, d f=6, p=0.603\right)$. The percentage of drying using a tumble-dryer increased in proportion to the increasing the ratio of PSS use from PW-only to PSS-only; tumble-dryer use in each group was 7.0 percent, 12.3 percent, and 22.2 percent, respectively. Meanwhile, the ratio of respondents who feel it is necessary to use a tumble-dryer are shown in Figure $6 \mathrm{~b}$. The results revealed that the 
number of respondents who want to use a tumble-dryer generally increases as the frequency of PSS use increases with statistically significant differences $\left(\chi^{2}=129.430, d f=6, p=0.000\right)$. The percentage of respondents who feel the necessity of using a tumble-dryer when doing the laundry in each group was 40.3 percent, 47.8 percent, and 100 percent, respectively.

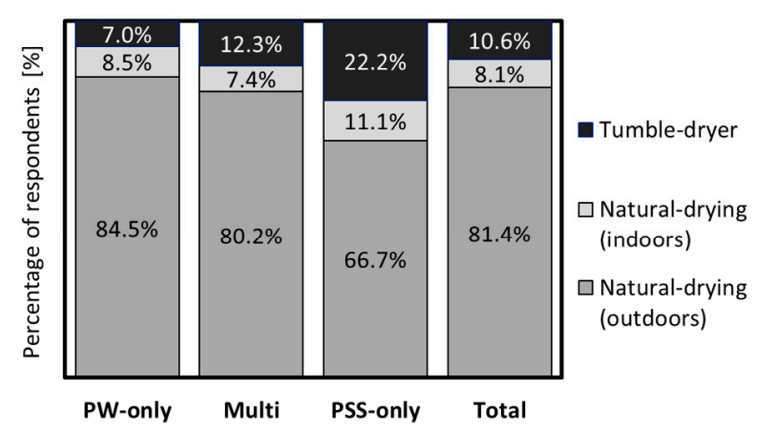

(a)

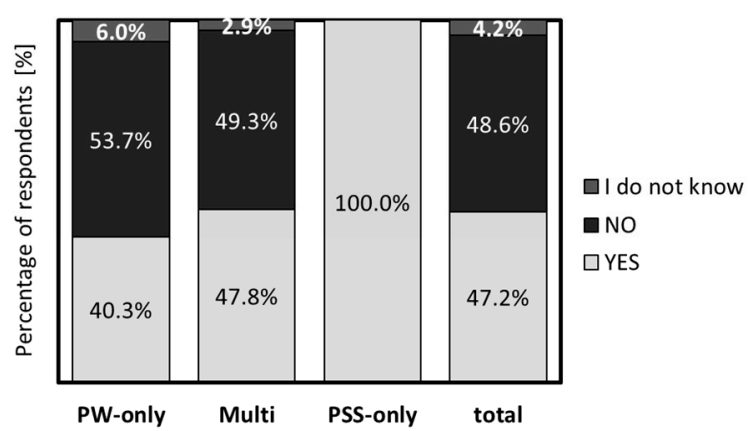

(b)

Figure 6. Drying laundry: (a) The method to dry laundry ( $\mathrm{n}=192)$; (b) Necessity of using a tumble-dryer $(\mathrm{n}=192)$.

Responses on the reason for use of CL and SL are shown in Figure 7a,b. Overall, the main reason for using CL and LS was "I do not have a washer" (70.4 percent from of the total respondents) and "I want my clothes to be ironed (to receive services)" (44.9 percent of the total), respectively. Examining the differences in the reasons for CL use, most respondents indicated that they do not have a washer as the reason for $\mathrm{CL}$ use, regardless of the group. There were no statistically significant differences between the groups $\left(\chi^{2}=3.842, d f=3, p=0.280\right)$. Meanwhile, the differences in the reason for LS use showed statistical significance $\left(\chi^{2}=21.662, d f=6, p=0.001\right)$. In terms of LS use, roughly 75 percent of the respondents in PSS only that owned a PW group (PSS-only w/ PW) indicated they want to receive services such as ironing, and this figure was 48.5 percent in the multi group. However, in the case of PSS only but not owning a PW group (PSS-only w/o PW), respondents who use "ironing" represented only 27.3 percent. Here, the reason that respondents who own a PW in the multi group and the PSS only w/PW group answered "I do not have a washer" while having PW might be that they are living in Bangkok without PW away from the home in which PW is installed (For details, refer to the result of in-depth interviews in Section 4.3).

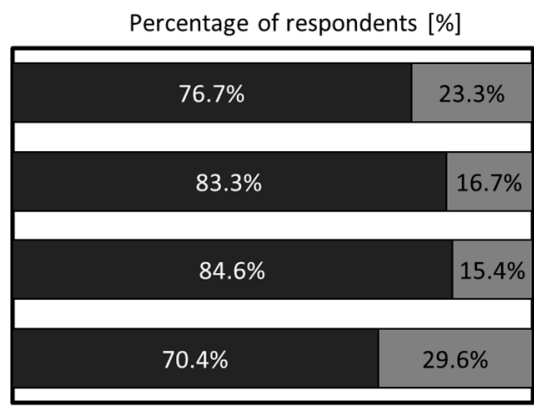

(a)

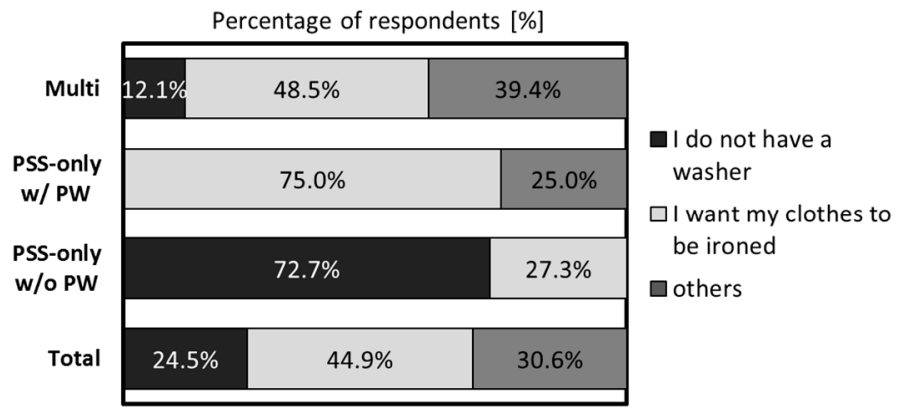

(b)

Figure 7. The reason for the use of PSS: (a) The reason for coin-operated laundromats (CL) use ( $\mathrm{n}=103)$; (b) The reason for laundry services (LS) use $(n=49)$.

\subsection{In-Depth Interview Survey Results 1: Laundry Habits}

In terms of the number of wears before the clothing item is washed, respondents who generally wear their clothes only once accounted for 87.8 percent of the total, while the rest of total interviewees indicated that they wear items more than twice. However, they indicated that it depends on the type of 
clothing. In the case of pajamas (27.7 percent), skirts, and pants including jeans (12.3 percent), formal clothes (4.6 percent), and sweaters and jackets ( 3.0 percent), they can be worn for a longer period of time. Meanwhile, sweaty clothes such as sportswear (3.1 percent) were a type of clothing that have to be changed in less than a day.

Over 90 percent of respondents were satisfied with drying their laundry naturally. However, 16 respondents indicated that they were not keen on the bad smell caused by drying laundry during the rainy seasons, regardless of whether they were satisfied about natural drying. Among the solutions suggested by the respondents, the most popular was "to use CL for drying laundry during rainy seasons" (37.5 percent), followed by "to take laundry back inside (31.3 percent), "to rewash" (18.8 percent), and "to rehang laundry until completely dry" (12.5 percent). Some approximately 15 percent of all respondents indicated that damage to clothes such as discoloration and stiffness caused by the strong sunlight is another problem with natural drying.

In terms of the capacity of PW, of the 32 respondents who own a PW, 59.4 percent had a 10-12 kg washer and 28.1 percent owned a $6-9.5 \mathrm{~kg}$ washer. When they do the laundry using a PW, they generally use cold water without controlling the temperature of the water. In general, there is no option to use warm or heated water in the washers sold in Thailand. Water temperature related to laundry habits shows a similar trend to several Asian countries, such as China, South Korea, and Japan, which is completely different from laundry habits in E.U. countries and the U.S. [2,9].

\subsection{In-Depth Interview Survey Results 2: Assessing the Role of Product-Service System in Laundry Habits}

Figure 8 shows intended use and frequency of use for each method of laundry, PW, CL, LS, and HW. The results revealed that responses related to the actual situation of using these methods have strong differences compared to the responses from the questionnaire. However, there was no significant difference in the use rate between the results of the two surveys. According to the results of the in-depth interviews, use rates of PW, CL, LS, and HW were 71.0 percent, 53.6 percent, 34.8 percent, and 21.7 percent, respectively.

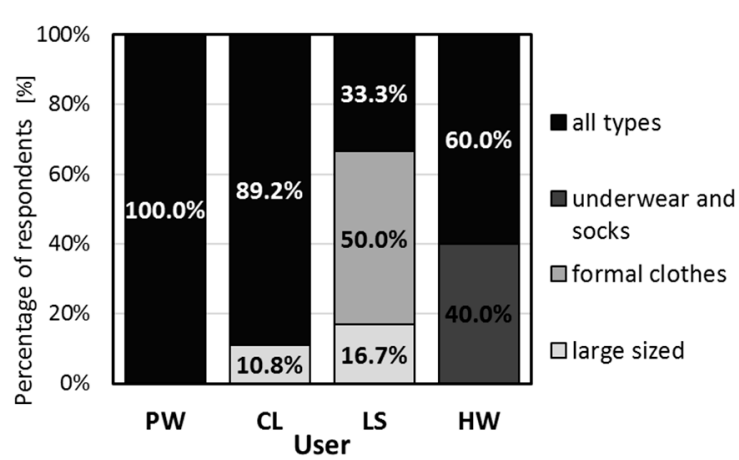

(a)

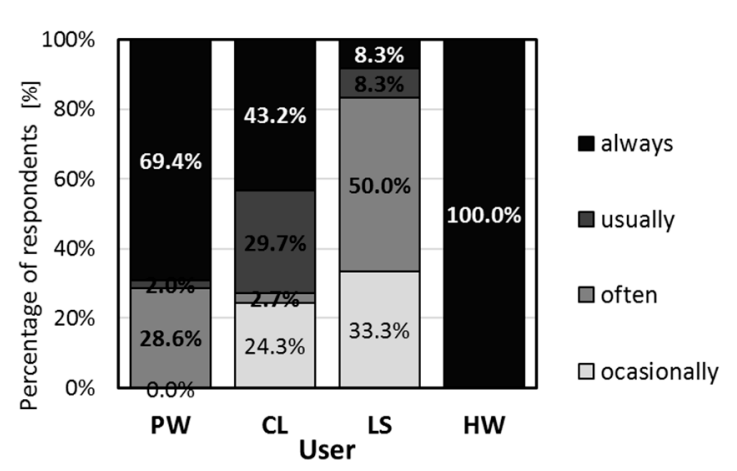

(b)

Figure 8. Laundry methods: (a) Intended use $(n=69$, multiple responses); (b) Frequency of use $(n=69$, multiple responses).

With respect to the intended use, PW was used for all the type of clothing and fabric. As with PW, CL was also used for all types of laundry by 89.2 percent of the CL users, the remaining 10.8 percent used CL for washing large-size laundry. LS was used for many other purposes, washing formal clothes was the most frequent (50.0 percent of the total LS users), followed by large-size laundry with 16.7 percent. In the case of $\mathrm{HW}, 60.0$ percent of the respondents indicated that they washed all the types of clothing and fabric by hand, and the remaining 40.0 percent indicated that they wash underwear and socks themselves. Even though more than half of these respondents replied that they do HW regardless of the type, all but one who did HW answered that they were actually using PW or PSS (Table A2). 
Moreover, the frequency of use, the ratio of respondents who "always" use, in each method of laundry, PW, CL, LS, and HW was 69.4 percent, 43.2 percent, 8.3 percent, and 100 percent, respectively. The ratio of users who "always" and "usually" do PW and CL was 71.4 percent and 72.9 percent, respectively. Meanwhile, in the case of respondents who use LS, the largest ratio of residents was users who indicated they use LS "often" (50 percent) followed by those use it "occasionally" (33.3 percent). This reveals that PW and CL are used routinely, while LS is used on special occasions.

Additionally, to clarify the role of each method, laundry patterns using PW, CL, and LS were organized based on the results of the in-depth interviews (Table A2), as shown in Table 2. In the table, the rows show the actual methods and reasons for use. The columns show the intended use, which is divided into main usage and sub-usage, such as the type of laundry and amount of time required. A total of twenty types of use patterns were identified in the survey. Regardless of the laundry pattern, PW was used as a main method for washing all types of laundry, while CL and LS were used as an additional method to improve the quality of laundry, to reduce time and effort, or to provide an alternative method to PW. However, the role of each method varied with the different lifestyle situations of the respondents.

Table 2. Use patterns of private washers (PW), coin-operated laundromats (CL), and laundry services (LS) $(\mathrm{n}=69)$.

\begin{tabular}{|c|c|c|c|c|c|c|c|c|c|}
\hline \multicolumn{2}{|r|}{ Use Patterns } & \multirow[b]{2}{*}{ No. } & \multirow{2}{*}{$\begin{array}{l}\text { Main } \\
\text { Usage }\end{array}$} & \multicolumn{5}{|c|}{ Sub Usage } & \multirow[b]{2}{*}{ HW (No.) } \\
\hline $\begin{array}{c}\text { Actual } \\
\text { Methods }\end{array}$ & Reason for Use & & & $\begin{array}{c}\text { All } \\
\text { Types }\end{array}$ & $\begin{array}{l}\text { Formal } \\
\text { Clothes }\end{array}$ & Large-Size & $\begin{array}{l}\text { Busy } \\
\text { Time }^{1}\end{array}$ & Drying & \\
\hline PW-only & $\begin{array}{c}\text { No intention and necessary about } \\
\text { using PSS }\end{array}$ & 17 & PW & & & & & & Underwear (1) \\
\hline \multirow{7}{*}{ PW-mainly } & \multirow{2}{*}{$\begin{array}{l}\text { Different preferences between } \\
\text { family members }\end{array}$} & 1 & PW & $\mathrm{CL}$ & & & & & \\
\hline & & 1 & PW & LS & & & & & \\
\hline & No experience/intention LS & 4 & PW & & & $\mathrm{CL}$ & & $\mathrm{CL}$ & \\
\hline & Living nearby a new PSS shop & 1 & PW & $\mathrm{CL}$ & & & & & \\
\hline & \multirow{3}{*}{ Convenience of using PSS } & 6 & PW & & LS & & & & Always (1) \\
\hline & & 2 & PW & & & LS & & & Underwear (1) \\
\hline & & 3 & PW & & LS & $\begin{array}{l}\mathrm{CL} \\
\mathrm{LS} \\
\end{array}$ & LS & $\mathrm{CL}$ & \\
\hline \multirow{4}{*}{ PSS-mainly } & \multirow{4}{*}{$\begin{array}{c}\text { Living in Dorm/Bangkok (leaving } \\
\text { hometown) }\end{array}$} & 8 & $\mathrm{CL}$ & PW & & & & & \\
\hline & & 1 & & PW & & & $\mathrm{CL}$ & & $\begin{array}{l}\text { Always/all } \\
\text { types (1) }\end{array}$ \\
\hline & & 2 & LS & PW & & & & & always (1) \\
\hline & & 3 & $\mathrm{CL}$ & PW & & & LS & & \\
\hline \multirow{8}{*}{ PSS-only } & \multirow{2}{*}{ Living in Dorm/Bangkok } & 7 & $\mathrm{CL}$ & & & & & & Always (4) \\
\hline & & 3 & $\mathrm{CL}$ & & LS & & LS & & \\
\hline & \multirow{3}{*}{ No space to install } & 1 & & & LS & $\mathrm{CL}$ & & & Always (1) \\
\hline & & 1 & LS & & & & & & \\
\hline & & 1 & & LS & & & & & \\
\hline & $\begin{array}{c}\text { No space to install/Not necessary } \\
\text { PW/No intention LS }\end{array}$ & 5 & $\mathrm{CL}$ & & & & & & \\
\hline & Not necessary of PW/Living alone & 1 & & & & LS & & & Always (1) \\
\hline & HW-only user & 1 & & & & & & & Always (1) \\
\hline
\end{tabular}

${ }^{1}$ Busy time means times in which there is not enough time to do the laundry, such as during exams. ${ }^{2} \mathbf{P W}, \mathbf{C L}$, and LS indicates the use of PW, CL, and LS, respectively.

Specifically, seventeen respondents used PW-only; they had no intention or necessity to use CL or LS. All these respondents indicated that PW is sufficient for their laundry. Also, a total of PW-mainly users by eighteen respondents used PSS to satisfy particular needs that could not be met by PW. There were four reasons for using PSS: different preferences for laundry methods among family members, no experience or intention to use other methods, living nearby a new PSS shop that had just opened, or convenience. Among them, the respondents who choose different methods between family members and who live nearby a new PSS shop used CL or LS in the same manner as 
PW. And the remaining two patterns of respondents used PSS to reduce the effort and time to wash laundry. For example, CL was used to dry laundry quickly or to wash large-size laundry easily, LS was used when additional services such as ironing formal clothes or washing and drying large loaded laundry was required. Twenty-four respondents who usually used CL or LS as an alternative to PW in order to live in dormitories or other residences away from home for study or work was the most widely observed pattern. This use pattern was seen among the respondents that used PSS-mainly and PSS-only. They had no choice but to use PSS to adapt to a new life without PW. Among them, PSS-mainly users by fourteen respondents used PW when they return to their hometown, but they do not feel the need to use PSS while they are using PW. They tended to use LS when they did not have enough time to do laundry. In addition, HW was used for saving money while living in Bangkok or for the cleanliness. The rest of PSS-only users by eight respondents used CL or LS for two reasons: living in a house with no space to install PW, and no intention to use PW or other methods because of living alone. A total of two respondents answered that they do laundry mainly or only by HW because they prefer cleanliness. One of those two respondents used LS only for washing and drying large-size items.

\section{Discussion and Conclusions}

The results indicated that laundry habits of Bangkok have the following characteristics. Even though the use of washers is becoming more common, some respondents still pre-wash their clothes by hand before using a washer to ensure the quality of the laundry, such as cleanliness. In terms of the capacity of PW, more than half of the respondents in the depth-interviews had over $10 \mathrm{~kg}$ load capacity washers. When using a washer for laundry, they generally use cold water, and there are, in general, no options to control the temperature of the water in the washers sold in Thailand. And most (87.8 percent) of the respondents generally dry their laundry naturally instead of using tumble-dryers. During the rainy season, some respondents bring their laundry to CL and use tumble-dryers in order to dry quickly. The tendency of using tumble-dryers also changes depending on the usage of PSS. The respondents who use PSS feel the necessity of using tumble-dryer more than those who only use PW. Moreover, most of the respondents indicated that they generally wear their clothing only once before the laundry, except the items which can be worn for a longer period of time such as pajamas, skirts and pants, formal clothes, sweaters, and jackets.

Among the various laundry options, PW is the most commonly used to do laundry, and CL and LS are used as an additional option. In the case of PSS usage, there was a slight difference in the motivation for usage between CL and LS. The groups who were in PSS-only and multi groups commonly used CL because they did not have a PW, that is, CL was used to overcome the physical limitation of space, while LS was used for additional services, such as ironing. Considering the intended use and the timing, 20 types of use patterns were identified from the survey. The most widely observed use pattern in Bangkok was the use of CL as an alternative to PW instead of buying a new machine for a new life in dormitories or other residences away from home. At that time, HW was also used for saving money while living in Bangkok, or for the cleanliness. Meanwhile, many respondents use PSS effectively for saving time and effort as well as increasing the quality of laundry, which resembles the use pattern of Japanese consumers [17].

These details related to the typical characteristics of laundry habits in Bangkok are very useful to estimate and define the parameter for quantifying environmental impact factors: the general process for laundry, load capacity of washer, water temperature for laundry, the use of tumble-dryer, and the amount of clothing. Considering the environmental potential, the relationship between the PSS users and laundry habits was qualitatively analyzed. The group who uses PSS frequently tended to do laundry less often than those who only use PW. Frequent PSS users adopted the use of tumble-dryers more often, and the need to use was high compared to others who do not use PSS. The need for even more services is also expected to increase among the PSS users. When these aspects are considered, the use of PSS could help to reduce the annual frequency of laundry at present. On the other hand, 
there is a high possibility that the use of PSS can increase the energy consumption and environmental loads because of the increase of the demands for additional services.

This study revealed that PSS are used in various ways to match the needs and preferences of users (Table 2) and the requirements to enhance the quality of its service have also been detailed (Table A3). The need to improve the quality of laundry is expected to increase with the improvement of quality of living in Bangkok in the near future. Indeed, this study shows similar results with a past study that PSS can enhance the functionality and quality of the service [24]. At the same time, a change of consumer behaviors related to the use of PSS determines the resulting energy consumption and environmental burdens $[18,25]$. It means that the use of CL and LS can have an effect on environment, therefore laundry habits related to use of PSS have been analyzed to clarify the impact of environmental factors in Bangkok. It is also a significant method for consumers to make environmentally sustainable choices while increasing their environmental awareness at the same time [26,27]. However, further information to evaluate environmental burdens and energy consumption by the use of PSS, such as the source of energy use, the use of water, and the use of laundry detergents, is yet to be obtained and remained as a limitation of this study. To propose an appropriate use of PSS to encourage sustainable consumption and production systems, a quantitative analysis of the environmental impacts of laundry habits should be done as a future task.

Author Contributions: Conceptualization, D.M., E.A., and M.H.; methodology, D.M., E.A., and M.H.; formal analysis, D.M.; investigation, D.M. and E.A.; writing-original draft preparation, D.M.; writing-review and editing, D.M., E.A., and M.H.; visualization, D.M.; supervision, M.H.; project administration, D.M. and M.H.; funding acquisition, M.H.

Funding: This research was supported by the Environment Research and Technology Development Fund (S-16) of the Environmental Restoration and Conservation Agency.

Acknowledgments: We would like to express our gratitude to Pongsun, B. of Transportation Institute, Chulalongkorn University in Thailand, and on-site researchers (each name is Chawan, A., Rungravee, P., and her sister, Ranaporn, T., and Thitiwut, M.) for their kind and generous support to our study.

Conflicts of Interest: The authors declare no conflict of interest. 


\section{Appendix A}

Table A1. A list of acronyms used in this paper.

\begin{tabular}{|c|c|}
\hline Washer & Washing machine \\
\hline PSS & Product-Service System \\
\hline Laundry PSS & PSS associated with laundry \\
\hline GHG & Greenhouse gas \\
\hline PNTA & Prefer not to answer \\
\hline $\mathrm{PW}, \mathrm{PW}$ & Private washing machines \\
\hline $\mathrm{CL}, \mathrm{CL}$ & Coin-operated (self-service) laundromats \\
\hline LS, LS & Laundry services \\
\hline HW & Hand washing \\
\hline PW-only & The group that uses private washing machines (PW) only \\
\hline Multi & The group that uses both of private washing machines (PW) and Product- Service system (PSS) \\
\hline PSS-only & The group that uses product-service system (PSS) only \\
\hline $\mathrm{PW}+\mathrm{CL}$ & $\begin{array}{c}\text { The group that uses both private washing machines (PW) and coin-operated self-service } \\
\text { laundromats (CL) }\end{array}$ \\
\hline PW+LS & The group that uses both private washing machines (PW) and laundry services (LS) \\
\hline $\mathrm{PW}+\mathrm{CL}+\mathrm{LS}$ & $\begin{array}{c}\text { The group that uses private washing machines (PW) together with coin-operated self-service } \\
\text { laundromats (CL) and laundry services (LS) }\end{array}$ \\
\hline $\mathrm{CL}+\mathrm{LS}$ & The group that uses both coin-operated self-service laundromats (CL) and laundry services (LS) \\
\hline CL-only & The respondent who uses coin-operated self-service laundromats (CL) only \\
\hline LS-only & The respondent who uses laundry services (LS) only \\
\hline HW-only & The respondent who do laundry by hand (HW)only \\
\hline $\mathrm{n}$ & The number of samples \\
\hline No. & The number of respondents \\
\hline$x^{2}$ & Chi-squared value \\
\hline$d f$ & degrees of freedom \\
\hline$p$ & P-value \\
\hline $\mathrm{w} /$ & With \\
\hline $\mathrm{w} / \mathrm{o}$ & Without \\
\hline $\min$. & Minute \\
\hline OCC. & Occasionally \\
\hline Dorm. & Dormitory \\
\hline (B) & Using in busy time \\
\hline (D) & Using for drying by tumble-dryer \\
\hline Q. & Quality \\
\hline
\end{tabular}


Table A2. The details of use patterns of private washers (PW), coin-operated laundromats (CL), and laundry services (LS).

\begin{tabular}{|c|c|c|c|c|c|c|c|c|c|c|c|c|}
\hline \multirow{2}{*}{\multicolumn{2}{|c|}{ Group ${ }^{1}$}} & \multirow{2}{*}{ No. ${ }^{2}$} & \multirow{2}{*}{$\begin{array}{c}\text { Actual } \\
\text { Methods }\end{array}$} & \multirow{2}{*}{$\begin{array}{l}\text { Reason for Use: Lifestyle Changes or } \\
\text { Preferences }{ }^{4}\end{array}$} & \multicolumn{2}{|c|}{$\mathrm{HW}$} & \multicolumn{2}{|c|}{ PW } & \multicolumn{2}{|c|}{ CL } & \multicolumn{2}{|c|}{ LS } \\
\hline & & & & & Types $^{5}$ & Frequency ${ }^{5}$ & Types ${ }^{5}$ & Frequency ${ }^{5}$ & Types $^{5}$ & Frequency ${ }^{5}$ & Types $^{5}$ & Frequency $^{5}$ \\
\hline \multirow{10}{*}{ PW-only } & \multirow{10}{*}{ PW-only } & \multirow{5}{*}{14} & \multirow{6}{*}{ PW-only } & Housekeeper do (2) & & & & & & & & \\
\hline & & & & Preferring self-laundry (2) & & - & All types (14) & Always (14) & - & - & - & - \\
\hline & & & & Avoiding share with others (2) & & & & & & & & \\
\hline & & & & Having experience (3) & & & & & & & & \\
\hline & & & & No experience/intention PSS (6) & & & & & & & & \\
\hline & & 1 & & - & All types (1) & Always (1) & All types (1) & OCC. (1) & - & - & - & - \\
\hline & & \multirow{2}{*}{3} & \multirow{2}{*}{$\mathrm{PW}+\mathrm{CL}$} & No intention to use PSS (2) & & \multirow[t]{2}{*}{ - } & \multirow{2}{*}{ All types (3) } & \multirow{2}{*}{ Occasionally (3) } & large-size (1) & OCC. (1) & - & - \\
\hline & & & & No good shop nearby (1) & & & & & All types (2) & OCC. (D)(2) & & \\
\hline & & 3 & PW+LS & - & - & - & All types (3) & OCC. (3) & - & - & Formal clothes (3) & Often (3) \\
\hline & & 1 & LS-only & Living alone, needless of $\mathrm{PW}$ & All types (1) & Always (1) & - & - & - & - & large-size (1) & OCC. (1) \\
\hline \multirow{23}{*}{ Multi } & \multirow{11}{*}{$\mathrm{PW}+\mathrm{CL}$} & \multirow{4}{*}{9} & \multirow{4}{*}{$\mathrm{PW}+\mathrm{CL}$} & Living in Dorm ${ }^{1}$. (6)/No intention LS (2) & - & - & All types (6) & Often (6) & All types (6) & Usually (6) & - & - \\
\hline & & & & $\begin{array}{l}\text { Living in Dorm, HW: using for saving } \\
\text { money (1) }\end{array}$ & All types (1) & Always (1) & All types (1) & Often (1) & All types (1) & OCC. (B)(1) & & - \\
\hline & & & & New shop is opened (1) & - & - & All types (1) & Usually (1) & All types (1) & Usually (1) & - & - \\
\hline & & & & No experience/intention LS (1) & - & - & All types (1) & Always (1) & Large-size (1) & OCC. (1) & - & - \\
\hline & & \multirow{3}{*}{3} & \multirow{3}{*}{$\mathrm{PW}+\mathrm{CL}+\mathrm{LS}$} & \multirow{2}{*}{ Having PW (2) } & - & - & All types (2) & Always (2) & All types (2) & OCC. (D)(2) & Formal clothes (1) & Often (1) \\
\hline & & & & & & & & & & & Large-size (1) & OCC. (1) \\
\hline & & & & Living in Dorm (1) & & & All types (1) & Often (1) & All types (1) & Usually (1) & All types (1) & OCC (B) (1) \\
\hline & & 1 & $\mathrm{PW}+\mathrm{LS}$ & Having PW (1) & All types (1) & Always (1) & All types (1) & Always (1) & - & - & Formal clothes (1) & Often (1) \\
\hline & & 1 & PW-only & No intention PSS (1) & All types (1) & Always (1) & All types (1) & Always (1) & - & - & - & - \\
\hline & & 3 & CL-only & Preferring self-laundry, No intention LS (1) & - & - & - & - & All types (1) & Always (1) & - & - \\
\hline & & & & Living in Dorm. (2) & Underwear (2) & Always (2) & - & - & All types (2) & Always (2) & - & - \\
\hline & & & & No experience/intention CL (3) & - & - & All types (3) & Always (3) & - & - & Formal clothes (2) & Often (2) \\
\hline & & & & & & & & & & & Large-size (1) & OCC. (1) \\
\hline & $\mathrm{PW}+\mathrm{LS}$ & 5 & PW+LS & $\begin{array}{l}\text { Different laundry preferences between } \\
\text { family members (1) }\end{array}$ & - & - & All types (1) & Always (1) & - & - & All types (1) & Always (1) \\
\hline & & & & $\begin{array}{l}\text { Living in Dorm., No experience/intention } \\
\text { CL (1) }\end{array}$ & $\begin{array}{l}\text { Underwear and } \\
\text { socks (1) }\end{array}$ & - & All types (1) & Often (1) & & & All types (1) & Usually (1) \\
\hline & & & & Living in Dorm. (2) & - & - & All types (2) & Often (2) & All types (2) & Always (1) & Always (1) & OCC. (B) (1) \\
\hline & & 3 & $\mathrm{PW}+\mathrm{CL}+\mathrm{LS}$ & & & & & & & OCC. (B)(1) & Formal clothes (1) & Often (1) \\
\hline & & & & Preferring self-laundry (1) & - & - & All types (1) & Always (1) & Large-size (1) & OCC. (1) & All types (1) & OCC.(B) (1) \\
\hline & $\mathrm{PW}+\mathrm{CL}+\mathrm{LS}$ & 1 & $\mathrm{PW}+\mathrm{CL}$ & $\begin{array}{l}\text { Different laundry preferences between } \\
\text { family members }\end{array}$ & - & - & All types (1) & Always (1) & All types (1) & Always (1) & - & - \\
\hline & & 1 & PW-only & - & Underwear (1) & - & All types (1) & Always (1) & - & - & - & - \\
\hline & & 1 & $\mathrm{PW}+\mathrm{LS}$ & - & Underwear (1) & - & All types (1) & Always (1) & - & - & Large-size (1) & OCC. (1) \\
\hline & & 2 & $\mathrm{CL}+\mathrm{LS}$ & Preferring LS (2) & - & - & - & - & All types (2) & Always (2) & Formal clothes (1) & Often (1) \\
\hline & & & & & & & & & & & All types (1) & OCC.(B)(1) \\
\hline
\end{tabular}


Table A2. Cont.

\begin{tabular}{|c|c|c|c|c|c|c|c|c|c|c|c|c|}
\hline \multirow{2}{*}{\multicolumn{2}{|c|}{ Group $^{1}$}} & \multirow{2}{*}{ No. ${ }^{2}$} & \multirow{2}{*}{$\begin{array}{c}\text { Actual } \\
\text { Methods }^{3}\end{array}$} & \multirow{2}{*}{$\begin{array}{l}\text { Reason for Use: Lifestyle Changes or } \\
\text { Preferences }{ }^{4}\end{array}$} & \multicolumn{2}{|c|}{ HW } & \multicolumn{2}{|r|}{ PW } & \multicolumn{2}{|c|}{ CL } & \multicolumn{2}{|c|}{ LS } \\
\hline & & & & & Types $^{5}$ & Frequency ${ }^{5}$ & Types $^{5}$ & Frequency ${ }^{5}$ & Types $^{5}$ & Frequency ${ }^{5}$ & Types $^{5}$ & Frequency ${ }^{5}$ \\
\hline \multirow{7}{*}{$\begin{array}{l}\text { PSS-only } \\
\text { w/PW }\end{array}$} & CL+LS & 0 & - & - & - & - & - & - & - & - & - & - \\
\hline & \multirow{4}{*}{ CL-only } & \multirow[t]{2}{*}{1} & \multirow{2}{*}{$\mathrm{PW}+\mathrm{CL}$} & Living in Dorm. & \multirow[b]{3}{*}{-} & \multirow[t]{2}{*}{-} & \multirow[t]{2}{*}{ All types (1) } & \multirow[t]{2}{*}{ Often (1) } & \multirow[t]{2}{*}{ All types (1) } & \multirow[t]{2}{*}{ Usually (1) } & \multirow[t]{2}{*}{ - } & \multirow[t]{2}{*}{ - } \\
\hline & & & & LS: Not suitable to lifestyle & & & & & & & & \\
\hline & & 1 & CL+LS & Living in Dorm. & & - & - & - & All types (1) & Always (1) & Formal clothes (1) & Often (1) \\
\hline & & 1 & (HW-only) & HW: Preferred for cleanliness & All types (1) & Always (1) & - & - & - & - & - & - \\
\hline & \multirow{2}{*}{ LS-only } & \multirow{2}{*}{1} & \multirow{2}{*}{$\mathrm{PW}+\mathrm{LS}$} & Living in Dorm. & - & \multirow[t]{2}{*}{-} & \multirow{2}{*}{ All types (1) } & \multirow{2}{*}{ Often (1) } & \multirow[t]{2}{*}{-} & \multirow[t]{2}{*}{ - } & \multirow[t]{2}{*}{ All types (1) } & \multirow{2}{*}{ Usually (1) } \\
\hline & & & & Having experience/No intention CL & & & & & & & & \\
\hline \multirow{12}{*}{$\begin{array}{l}\text { PSS-only } \\
\text { w/o PW }\end{array}$} & \multirow{4}{*}{ CL+LS } & 1 & $\mathrm{CL}+\mathrm{LS}$ & No PW & All types (1) & Always (1) & - & - & Large-size (1) & Often (1) & Formal clothes (1) & Often (1) \\
\hline & & 1 & CL-only & Prefer self-laundry & - & - & - & - & All types (1) & Always (1) & - & - \\
\hline & & & & CL: suitable to lifestyle & & & & & & & & \\
\hline & & 1 & LS-only & - & - & - & - & - & - & - & Formal clothes (1) & Often (1) \\
\hline & & & & No space to install (1) & & & & & & & & \\
\hline & & & & Do not want PW (2) & & - & - & - & All types (5) & Always (5) & - & - \\
\hline & & 8 & CL-only & No intention LS (2) & & & & & & & & \\
\hline & CL-only & 0 & ent & HW: using for cleanliness (1) & All types (2) & Always (2) & - & - & All types (1) & Always (1) & - & - \\
\hline & & & & No space to install (1) & 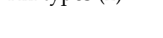 & 等 & & & & & & \\
\hline & & & & No intention LS (1) & $\begin{array}{l}\text { Socks and shirts } \\
\text { (1) }\end{array}$ & Always (1) & - & - & All types (1) & Always (1) & - & - \\
\hline & & 1 & $\mathrm{PW}+\mathrm{CL}$ & Living in Bangkok/ No intention LS & - & - & All types (1) & Often (1) & All types (1) & Usually (1) & - & - \\
\hline & LS-only & 1 & LS-only & No space to install & - & - & - & - & - & - & All types (1) & Always (1) \\
\hline
\end{tabular}

${ }^{1}$ Group was divided based on the answers from the questionnaire. ${ }^{2}$ Numbers in parentheses in the table (No.) indicates the number of respondents. ${ }^{3}$ Actual methods were classified based on the responses of the in-depth interview. ${ }^{4}$ Reason for using shows the motivations of using each method related to lifestyle changes or personal preferences. ${ }^{5}$ Types and frequency shows intended use and frequency of use, respectively. ${ }^{6}$ Dorm. and OCC. is the abbreviation for dormitory and occasionally, respectively. w/ and w/o $=$ "with" and "without," respectively. (B) and (D) shows busy time and using for drying by machine, respectively. 
Table A3. Opinions about the use of private washers (PW), coin-operated laundromats (CL), and laundry services (LS) by groups.

\begin{tabular}{|c|c|c|c|c|c|c|c|c|c|c|c|c|c|c|c|c|c|c|c|c|c|c|c|c|c|c|c|c|}
\hline & \multirow{3}{*}{\multicolumn{2}{|c|}{ Group }} & \multirow[b]{3}{*}{ No. } & \multirow[b]{3}{*}{$\begin{array}{l}\text { pros } \\
\text { and } \\
\text { cons }\end{array}$} & \multicolumn{8}{|c|}{ PW } & \multicolumn{8}{|c|}{ CL } & \multicolumn{8}{|c|}{ LS } \\
\hline & & & & & \multicolumn{3}{|c|}{$\begin{array}{l}\text { Technical } \\
\text { Quality }\end{array}$} & \multicolumn{2}{|c|}{$\begin{array}{l}\text { Functional } \\
\text { Quality }\end{array}$} & \multicolumn{3}{|c|}{$\begin{array}{c}\text { Service } \\
\text { Environment }\end{array}$} & \multicolumn{3}{|c|}{$\begin{array}{c}\text { Technical } \\
\text { Quality }\end{array}$} & \multicolumn{2}{|c|}{$\begin{array}{l}\text { Functional } \\
\text { Quality }\end{array}$} & \multicolumn{3}{|c|}{$\begin{array}{c}\text { Service } \\
\text { Environment }\end{array}$} & \multicolumn{3}{|c|}{$\begin{array}{c}\text { Technical } \\
\text { Quality }\end{array}$} & \multicolumn{2}{|c|}{$\begin{array}{l}\text { Functional } \\
\text { Quality }\end{array}$} & \multicolumn{3}{|c|}{$\begin{array}{c}\text { Service } \\
\text { Environment }\end{array}$} \\
\hline & & & & & 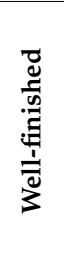 & $\begin{array}{l}\stackrel{\vec{J}}{\vec{\Xi}} \\
\text { 心 }\end{array}$ & $\begin{array}{l}\text { क्षे } \\
\text { ळँ } \\
\text { के }\end{array}$ & 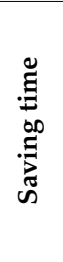 & 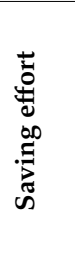 & 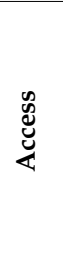 & $\overrightarrow{0}$ & 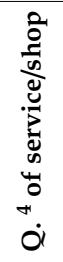 & 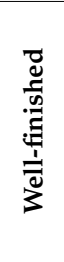 & 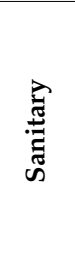 & $\begin{array}{l}\text { 胥 } \\
\text { ळू. } \\
\text { के }\end{array}$ & 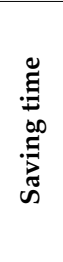 & 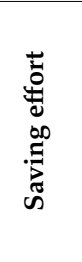 & 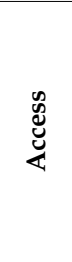 & $\overrightarrow{\tilde{\theta}}$ & 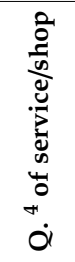 & 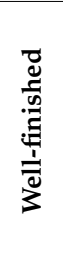 & 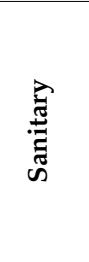 & $\begin{array}{l}\overrightarrow{\vec{z}} \\
\mathbb{\Xi} \\
\text { के }\end{array}$ & 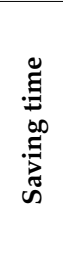 & 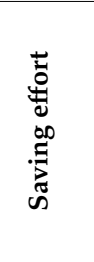 & $\begin{array}{l}\infty \\
\stackrel{8}{u} \\
\frac{\tilde{L}}{4}\end{array}$ & के & 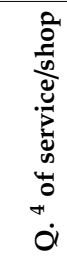 \\
\hline PW-only & \multicolumn{2}{|c|}{ PW-only } & 22 & $\begin{array}{l}\text { pros } \\
\text { cons }\end{array}$ & $\bigcirc$ & & $\bigcirc$ & 0 & 0 & & & & $\bullet$ & $\bullet$ & & $\bullet$ & ○ & $\bullet$ & & & 0 & 0 & 0 & & $\bullet$ & $\bullet$ & $\bullet$ & $\bullet$ \\
\hline \multirow{3}{*}{ Multi } & \multicolumn{2}{|c|}{$\mathrm{PW}+\mathrm{CL}$} & 17 & $\begin{array}{l}\text { pros } \\
\text { cons }\end{array}$ & & & & & & & & & 0 & $?$ & 0 & 0 & 0 & & & & 0 & & & $?$ & & & • & \\
\hline & \multicolumn{2}{|c|}{ PW+LS } & 5 & $\begin{array}{l}\text { pros } \\
\text { cons }\end{array}$ & & & & & & & & & & • & & & & & & & & & & & & & & 0 \\
\hline & \multicolumn{2}{|c|}{$\mathrm{PW}+\mathrm{CL}+\mathrm{LS}$} & 8 & $\begin{array}{l}\text { pros } \\
\text { cons }\end{array}$ & 0 & & & & & & & & 0 & 0 & 0 & 0 & 0 & & 0 & & & & & 0 & & & & 0 \\
\hline \multirow{6}{*}{ PSS-only } & \multirow{3}{*}{$\mathrm{w} / \mathrm{PW}$} & $\mathrm{CL}+\mathrm{LS}$ & 0 & $\begin{array}{l}\text { pros } \\
\text { cons }\end{array}$ & & & & & & & & & & & & & & & & & & & & & & & & \\
\hline & & CL-only & 4 & $\begin{array}{l}\text { pros } \\
\text { cons }\end{array}$ & & & & & & & & & 0 & $\bullet$ & $\bullet$ & $\bullet$ & • & 0 & 0 & & & & $?$ & $?$ & $?$ & & $\bullet$ & \\
\hline & & LS-only & 1 & $\begin{array}{l}\text { pros } \\
\text { cons }\end{array}$ & & & & & & & & & & & & & & & & & & & 0 & $\bigcirc$ & $\bigcirc$ & & & \\
\hline & \multirow{3}{*}{ w/o PW } & $\mathrm{CL}+\mathrm{LS}$ & 3 & $\begin{array}{l}\text { pros } \\
\text { cons }\end{array}$ & & & & & & & & & & & 0 & 0 & 0 & & & & & & & & & & • & O \\
\hline & & CL-only & 9 & $\begin{array}{l}\text { pros } \\
\text { cons }\end{array}$ & & & & & & & & & & $\bullet$ & 0 & 0 & 0 & & & & & & $\bullet$ & $\bullet$ & $\bullet$ & & $\bullet$ & $\bullet$ \\
\hline & & LS-only & 1 & $\begin{array}{l}\text { pros } \\
\text { cons }\end{array}$ & 0 & 0 & 0 & 0 & 0 & & & & & & & & & & & & & & 0 & 0 & 0 & & 0 & \\
\hline & \multirow{2}{*}{\multicolumn{2}{|c|}{ Total }} & & pros & 3 & 1 & 2 & 2 & 2 & 0 & 0 & 0 & 3 & 2 & 4 & 4 & 4 & 1 & 2 & 0 & 2 & 1 & 4 & 5 & 3 & 0 & 1 & 3 \\
\hline & & & & cons & 0 & 0 & 0 & 0 & 0 & 0 & 0 & 0 & 1 & 5 & 1 & 2 & 2 & 1 & 0 & 0 & 0 & 0 & 2 & 3 & 3 & 1 & 5 & 2 \\
\hline
\end{tabular}




\section{References}

1. Cullen, J.M.; Allwood, J.M. The role of washing machines in life cycle assessment studies: The dangers of using lca for prioritization. J. Ind. Ecol. 2009, 13, 27-37. [CrossRef]

2. Pakula, C.; Stamminger, R. Electricity and water consumption for laundry washing by washing machine worldwide. Energy Effic. 2010, 3, 365-382. [CrossRef]

3. Retamal, M.; Schandl, H. Dirty laundry in Manila: Comparing resource consumption practices for individual and shared laundering. J. Ind. Ecol. 2018, 22, 1389-1401. [CrossRef]

4. Tukker, A. Eight types of product-service system: Eight ways to sustainability? Expreiences from suspronet. Bus. Strateg. Environ. 2004, 13, 246-260. [CrossRef]

5. Heiskanen, E.; Jalas, M. Can services lead to radical eco-efficiency improvements? A review of the debate and evidence. Corp. Soc. Responsib. Environ. Manag. 2003, 10, 186-198. [CrossRef]

6. Mont, O.; Tukker, A. Product-Service Systems: Reviewing achievements and refining the research agenda. J. Clean. Prod. 2006, 14, 1451-1454. [CrossRef]

7. Mont, O.K. Clarifying the concept of product-service system. J. Clean. Prod. 2002, 10, 237-245. [CrossRef]

8. Laitala, K.; Klepp, I.G.; Boks, C. Changing laundry habits in Norway. Int. J. Consum. Stud. 2012, 36, $228-237$. [CrossRef]

9. Geetha, D.; Tyagi, R. Consumer behavior and fascinating challenges on household laundry and dishwashing. Tenside Surfactants Deterg. 2016, 53, 568-575. [CrossRef]

10. Geels, F.W.; Sovacool, B.K.; Schwanen, T.; Sorrell, S. The Socio-Technical Dynamics of Low-Carbon Transitions. Joule 2017, 1, 463-479. [CrossRef]

11. Golden, J.S.; Subramanian, V.; Irizarri, G.M.A.U.; White, P.; Meier, F. Energy and carbon impact from residential laundry in the United States. J. Integr. Environ. Sci. 2010, 7, 53-73. [CrossRef]

12. Lovins, A.B.; Lovins, L.H.; Hawken, P. A road map for natural capitalism. Harv. Bus. Rev. 1999. Available online: https://hbr.org/2007/07/a-road-map-for-natural-capitalism (accessed on 7 August 2019).

13. Barquet, A.P.; Seidel, J.; Seliger, G.; Kohl, H. Sustainability Factors for PSS Business Models. Procedia CIRP 2016, 47, 436-441. [CrossRef]

14. Bocken, N.M.P.; Short, S.W.; Rana, P.; Evans, S. A literature and practice review to develop sustainable business model archetypes. J. Clean. Prod. 2014, 65, 42-56. [CrossRef]

15. Halme, M.; Anttonen, M.; Hrauda, G.; Kortman, J. Sustainable evaluation of European household services. J. Clean. Prod. 2006, 14, 1529-1540. [CrossRef]

16. Halme, M.; Jasch, C.; Scharp, M. Sustainable homeservices? Toward household services that enhance ecological, social and economic sustainability. Ecol. Econ. 2004, 51, 125-138. [CrossRef]

17. Tukker, A.; Cohen, M.J.; Hubacek, K.; Mont, O. Sustainable consumption and production. J. Ind. Ecol. 2010, 14, 1-3. [CrossRef]

18. Amasawa, E.; Suzuki, Y.; Moon, D.; Nakatani, J.; Sugiyama, H.; Hirao, M. Designing interventions for behavioral shifts toward product sharing: The case of laundry activities in Japan. Sustainability 2018, 10, 2687. [CrossRef]

19. Survey on Consumption Trends. Available online: https://www.e-stat.go.jp/stat-search/files?page=1\&toukei= 00100405\&tstat $=000001014549 \&$ cycle $=0$ (accessed on 29 October 2018).

20. Housing Bangkok Style. Available online: https://www.jetro.go.jp/ext_images/jfile/report/07000366/ bangkokstyle_housing.pdf (accessed on 29 October 2018).

21. The Current Situation and Trend in Asia. Available online: https://www.meti.go.jp/report/tsuhaku2010/ 2010honbun_p/2010_02-3-2.pdf (accessed on 21 September 2018). (In Japanese).

22. Novianto, D.; Gao, W.; Kuroki, S. Review on People's Lifestyle and Energy Consumption of Asian Communities: Case Study of Indonesia, Thailand, and China. Energy Power Eng. 2015, 7, 465-476. [CrossRef]

23. Number of Population from Registration by Age Group and Region: 2007-2017. Available online: http: //statbbi.nso.go.th/staticreport/page/sector/en/01.aspx (accessed on 1 April 2019).

24. Kim, S.; Son, C.; Yoon, B.; Park, Y. Development of an innovation model based on a Service-oriented product service system (PSS). Sustainability 2015, 7, 14427-14449. [CrossRef] 
25. Hu, J.; Seliger, G. Case studies of sustainable PSS business Models for city mobility. In Product-Service Integration for Sustainable Solutions, Proceedings of the 5th CIRP International Conference on Industrial Product-Service Systems, Bouchum, Germany, 14-15 March 2013; Meier, H., Ed.; Springer: Berlin/Heidelberg, Germany, 2013; pp. 191-202.

26. Washing Machine-Webarchiv of the ETH Zurich. Available online: http://webarchiv.ethz.ch/sustainabilityv2/lehre/Sommerakademien/so2011/washies_report.pdf (accessed on 29 October 2018).

27. Gwozdz, W.; Nielsen, K.S.; Múller, T. An environmental perspective on clothing consumption: Consumer segments and their behavioral patterns. Sustainability 2017, 9, 762. [CrossRef]

(C) 2019 by the authors. Licensee MDPI, Basel, Switzerland. This article is an open access article distributed under the terms and conditions of the Creative Commons Attribution (CC BY) license (http://creativecommons.org/licenses/by/4.0/). 